Article

\title{
Conceptualising Design Fixation and Design Limitation and Quantifying Their Impacts on Resource Use and Carbon Emissions
}

\author{
Raphael Wasserbaur *(1) and Tomohiko Sakao () \\ Division for Environmental Technology and Management, Department of Management and Engineering, \\ Linköping University, 58183 Linköping, Sweden; Tomohiko.Sakao@LiU.se \\ * Correspondence: raphael.wasserbaur@liu.se; Tel.: +46-700-89-53-01
}

Received: 17 August 2020; Accepted: 23 September 2020; Published: 1 October 2020

check for updates

\begin{abstract}
Design for sustainability needs to apply a societal perspective. The purpose of this paper is to combine the concept of design fixation with higher levels of analysis. Design fixation is used to describe a blind adherence to known concepts during the design process. It is used mostly at the micro level of design with the focus on the activities of an individual designer or a group of designers. In this paper, design fixation gets conceptually lifted to the levels of the organisation and the institution. We ask how the understanding of design fixation helps to achieve higher resource efficiency. Examples of organisational and institutional design fixations are presented. A System Dynamics model is used to simulate the impacts of design fixation on resource use of a sociotechnical laundry systems. Applying this lens suggests that in order to solve societal design fixations, systemic parameters like infrastructure, business models, or policies need to be considered design parameters. The simulation results show that high-level design fixations can have significant impact on resource use.
\end{abstract}

Keywords: design fixation; design for sustainability; system dynamics; sociotechnical systems; systems perspective; environmental sustainability

\section{Introduction}

Decreasing resource use and the emissions of human activities to sustainable levels is one of today's major challenges. A considerable amount of research has focussed on understanding how to make products and services more resource efficient [1,2]. Yet, when applying a systems perspective, it becomes clear that many of society's needs are not just fulfilled through direct use of products and services but rather through a sociotechnical system (STS) in which products and services are embedded [3]. An STS consists of interconnected material objects such as infrastructure and products, as well as the services and legal systems necessary to provide the desired functionality. Given that technical systems are always embedded in organisational and social contexts that interact [3], improvements in product and service are an essential requirement, but not enough and deep and systemic changes are needed in STS for a sustainability transformation.

To tackle this problem, the features of an STS with the systems perspective, such as interactions and interdependencies between the system elements, have been indeed found increasingly relevant to tackle the sustainability issue over recent decades [4]. For instance, the Product/Service System (PSS) notion emerged due to the benefits of addressing products and their related services as one system [5]. Additionally, sustainable business models gained attention because not only product and service characteristics but also organisational and supply chain aspects etc. are important to environmental performance [6]. An even larger level of analysis has been applied in Olsson [7] or in Kanda, et al. [8] where the STS lens is used to identify potential for wider environmental improvements by combining 
technological and non-technological factors. Known characteristics of STS that make them difficult to reshape eventually towards more sustainability are lock-in and lock-out effects, path dependencies or knock-on effects [9,10].

Applying design thinking [11] on such a high level as an STS to design or redesign an STS in the sustainability context is not common in the literature on design for sustainability to date. However, it will uncover the interplays on the STS level and help us scrutinise the constraints, preconditions and assumptions that are usually brought down into element design (such as PSS and business model design) as a translation of the interplays. For instance, a leasing regulation that was found to limit a product-as-a-service business model from being designed for improved resource efficiency [12] could be investigated in the sustainability context. Addressing the interplays as design parameters is often a lost or unrecognised opportunity. To fill the void of holistic problem solving, design thinking [11], which has gained popularity and is built upon various scientific design theories, has potential. Among others, this unexploited potential could be clearly explained and further discussed by introducing the concept of design fixation to the level of STS. Design fixation refers to blind adherence to a set of concepts, limiting the output of the conceptual design process [13-15].

This article is motivated to improve designing at the societal level, i.e., deciding the characteristics of an element of a system or the whole system in ways that lead to adaptions of the dominant unsustainable STS towards less resource use. A product developer, a business model developer, and a policymaker are examples of designers. This is in line with Gero [16], who states, "Designers are change agents in society. Their goal is to improve the human condition in all its aspects through physical change". Looking at the current literature, design fixation was analysed mostly at the micro level of design, i.e., with the focus on the activities by an individual designer or a group of designers in one organization [15]. Design fixation is with important significance to many fields of design [17]. However, little knowledge is documented about phenomena corresponding to design fixations in the meta level of organisations. Such knowledge as to the "whats", "whys" and "hows" will be highly useful to improve STS designing. Interestingly, many of the remedies and the factors shown above are not directly applicable to STS design, although some are potentially applicable. In this article, we recognise the importance of design fixation for the sustainability challenge and therefore lift the design fixation concept from the individual to higher levels of analysis.

This paper aims to contribute to the literature of design for sustainability. The research objectives of this article are threefold. First, the concept of design fixation available in the literature is applied to higher levels of design, and its greater understanding is obtained for the above-mentioned unexploited potential for sustainability. Second, real-world solutions in the case of clothes washing are presented and analysed from the STS perspective to uncover opportunities and hindrances in designing them. Third, several concrete missed opportunities are quantitatively estimated in environmental terms. These are expected to shed light on the underexplored potential for improvement in designing an STS with decreased environmental impacts. The following research question is formulated:

\section{How Could the Understanding of Design Fixation Help to Achieve Higher Resource Efficiency of an STS?}

The remainder of this article is organised as follows: First, Section 2 introduces the two central concepts of this paper, STS and design thinking, with a focus on design fixation. Then, Section 3 presents a conceptual framework that extends the design fixation concept from the individual to higher levels of analysis. Next, Section 4 presents a case study of a sociotechnical laundry system in which the environmental impact of design fixations is simulated. Following that, Section 5 works out the contributions of this approach and relates the work to other fields. Finally, Section 6 concludes the article and points at avenues of future research. 


\section{Background}

\subsection{STS—Sociotechnical System}

There are multiple bodies of literature contributing to STSs. The various theories each have a different focus on what predominantly determines the evolution of an STS. Historically, research on STSs originates from the question of how the work environment affects human performance, such as in coal mines [18]. According to Hughes [19], elements of an STS can be categorised into physical artefacts, organisations, scientific research, legislative artefacts, and natural resources. In general, much research on STSs focusses on the relationship between society and technology. Similarly, in the theory of large technical systems, the relationship between actors and technology determines how systems develop over time. The actor-network theory sees that actors are more important in determining the development of STSs [20], whereas transition theory sees that STSs are determined through societal regimes [7].

Geels [21] defines STS "as the linkages between elements necessary to fulfil societal functions" (p. 900). Transformations of STSs are dynamic processes that occur on three levels: the niche, the regime and the landscape level. On the niche level radical innovations emerge, the regime level includes the set of rules represented by institutions that structure the STSs, and the landscape level comprises exogenous long-term aspects such as demographic trends, or climate change [22]. Within this three level-concept, design thinking seems to have potential to contribute to the niche and the regime level. This perspective suggests that society and technology co-evolve. It entails a broad research scope where STSs serve as a unit of analysis. In this line of research, there is also consensus that a main challenge is to understand how the STS components interact and how system change affects sustainability [23]: also, there is a common understanding that system complexity stems from feedback loops, self-organisation, and system hierarchies [23]. STS changes are a function of the interactions between technology, economy, institutions, human behaviour, as well as culture [23]. Burk [24] argues that STSs are the result of power struggles, and the interest group with the greater political power will be most impactful on shaping an STS.

The multi-level perspective is suitable to investigate societal systems such as urban transportation [7] or domestic heating [20], and how its components are interlinked. When thoroughly investigating, for example, the resource use of a product to obtain effective and efficient interventions, it is necessary to look at the product, the related services, consumer usage, material sourcing, production, and end-of-life operations in an STS. Advanced analyses may even compare various business model configurations and or policy changes when taking a long-term perspective.

We employ the STS as a unit of analysis for design fixation on the institutional level as described below. We narrow our scope to system components that are most relevant for the estimation of the environmental impact of specific consumer behaviour, such as lifecycle aspects of products and services, population dynamics or consumer behaviour.

\subsection{Design Thinking and Its Application to Sustainability}

Design thinking applies the principles of design to a broad set of challenges [25]. Finding creative ways of solving problems is an important part of it, as well as integrative and holistic types of thinking. Two famous examples of great design thinking are Thomas Edison's light bulb and Apple's iPod. Both examples are not just about a product but an entire eco-system around the product that makes it much more enjoyable [15]. Design thinking is about finding out the real needs and capabilities of people, also known as human-centred design. Typically, it is necessary to step back from a given problem and try to understand the real issues first. Design thinking first seeks to understand the problem and then finds a solution at a later stage [26]. Prototyping and participation with problem owners and divergent thinking are also key notions of design thinking. Thereby, design thinking is apt to solve so-called "wicked" problems. Some principles of design thinking, such as experimentation, [27] have been reported to be part of many developments and designs of sustainability-related STSs $[27,28]$ or in urban environments [29]. 
The ideal design thinking process is often described as an iterative process with multiple steps. The Stanford way of design thinking is framed into five stages: emphasise, define, ideate, prototype and test [30]. Norman uses similar terms, namely, observation, ideation, prototyping and testing [26]. A different way of seeing the design process is dividing it into two phases-finding the right problem and finding the right solution (the Double Diamond model of design). Yet another way to define the phases of design thinking comes from Brown and colleagues, who talk of the three innovation spaces of inspiration, ideation and implementation [25]. In the first stage, the designer needs to understand the problem at hand. The real underlying problem can be different from the apparent problem, and the designer needs to be quite certain that she/he understands the real problem. This step requires gathering data from the problem owners and an in-depth knowledge of the problem. Next, the second phase is about finding the patterns that are causing the problem, while the third phase requires formulating design principles that help to incur the right kind of behaviour among the target group. In the fourth step comes the prototyping phase, where something tangible is embodying possible solutions. Finally, the fifth phase is about testing and potentially starting a new iteration of the whole process [30].

As an example of research applying design thinking to a real-world challenge, Cole, et al. [31] discuss design thinking in the subject of the built environment and argue that the benefits of design thinking include a stronger theoretical framing by expanding the scope in the space dimension, that is, widening the boundary focus of a building from its site to the neighbourhood [31]. This framing is expected to help identify opportunities for synergistic interactions with other elements beyond the design object at hand. The hallmark of design thinking is that it brings in an expanded view to problem solving and points at several intervention points that could be missed otherwise. Similar thinking evoked through the systems perspective has been highlighted in literature such as industrial ecology [32] or industrial symbiosis [33].

Previous works have applied design thinking to the sustainability challenge. Clune and Lockrey [34] use a mixed approach. First, they applied an LCA to understand the areas where the underlying system of an elderly care centre caused the highest environmental impacts (i.e., the first diamond of finding the problem). In a second step, they found alternative practices through creative design thinking methods that supposedly helped to substantially mitigate the environmental impact in terms of the reduction of carbon emissions over a ten-year time frame (i.e., the second diamond of finding the solution). The result was a mix of new social practices and technical (e.g., energy usage) and organisational (e.g., procurement processes and planning) measures that alleviated the environmental impact from multiple angles [34]. This approach is an example where a wider perspective, in this case, an organisational perspective, was used to design an intervention that improved the environmental performance to a much larger degree than a purely technological solution could have done. A similar direction has been taken by Kanda, Sakao and Hjelm [8] who looked at environmental benefits that emerge when applying a large technical systems perspective. Geissdoerfer, Bocken and Hultink [6] adopt design thinking to enhance an existing sustainable business model innovation process by supporting the creation of additional value and including more stakeholders of relevance. Bocken et al. (2019) apply user-centeredness, participation, and experimentation to find creative ways to make business models more sustainable.

Shapira, et al. [35] point out that while design thinking was very useful in fostering creativity and holistic solutions, it does not inherently support sustainability. The authors suggest a "sustainable design thinking process" which particularly included steps focussing on sustainability issues. Their method was presented in a generic form and broadened the design thinking perspective from mainly human-centred to a long-term and systems perspective [35].

What the above-mentioned examples all have in common is they extended their scope in order to find superior solutions with a lower environmental impact. Yet, even though the existing research applies design thinking for the sustainability challenge, little research has been found that aims to identify opportunities for better design on an STS level. 


\subsection{Design Fixation}

Design fixation is an established concept in engineering design (see origins in [13]). Famous examples come from descriptions of large companies like Rolls-Royce and Sony, where design fixations lead to substantial delays in the product development of turbines or the CD players, respectively [36]. Design fixation is a critical barrier in the ideation stage for creating potential concepts towards design solutions, and thus it is to be avoided in implementing design thinking, where creativity is highly embraced. A classification of design fixations is available [15]: unconscious adherence, conscious blocking, and intentional resistance.

Unconscious adherence is, for instance, a phenomenon where designers commit to the concepts that they think of first without realising other concepts [37]. Conscious blocking, which also corresponds to the so-called "curse of experience" [15] or cognitive entrenchment [38] in other disciplines, may occur where experience leads to the development of decision rules, heuristics, etc. This may allow for quicker solution finding but at the same time may lead to a problem framing from this body of knowledge and may hamper the generation of new ideas [15,38]. Intentional resistance is a kind of nostalgia where previously successful designs are favoured over new ones, which may also be risk-averse behaviour [15]. This arises from a certain short-term bias where new developments or investments are not given enough time and are discarded before they can evolve. Historical examples may be the non-adoption of the metric system in America or holding on to outdated technologies [15].

The other categorisation of design fixation is conceptual versus knowledge-based fixation; the former refers to the situation where a single design concept is considered for a solution, while the latter refers to where knowledge only within one area is used [15].

Design fixations may occur for different reasons. In planned obsolescence [39], product developers deliberately choose shorter-life components to maintain or increase the income from selling products, which may be classified into conscious blocking. Further, concerning knowledge on requirements, engineering designers tend to focus on technically specified requirements [40]. This may also lead to unaccepted products due to their failure to consider unspoken customer needs that are widespread in marketing, which in turn may correspond to knowledge-based fixation with unconscious adherence.

Methods for preventing the various types of design fixations were summarised in a literature review [15]. A timely warning to consider all options is suggested for unconscious conceptual fixation [41], and including physical prototyping materials during the conceptual design to inform of phenomena in different domains is a possible remedy for unconscious knowledge fixation [15]. For conscious blocking, short breaks are considered useful [42]; also, design training methods, for example TRIZ [43], are possibly effective, and computer-assisted design is beneficial [44]. Intentional resistance is left with no known conceivable remedy but interdisciplinary cooperation, creativity exercises, or changes in beliefs [45]. Regarding practice in industry, based on interviews with expert designers, Crilly [46] categorised practices into five factors that discourage fixation: teamwork with other designers, systematic design methods, facilitation by experts, making of computational or physical models and expectations by clients.

As briefly reviewed above, design fixation was mostly analysed at the micro level of design and mainly in an industrial or manufacturing context, i.e., focusing on the activities of an individual designer or a group of designers in one manufacturing organisation. Considering the importance of the systems perspective and the STS, applying the concept of design fixation and its associated knowledge to the higher levels is expected to create useful insights in the sustainability context.

\section{Conceptual Framework for Design Fixation in the Sustainability Context}

Whereas design fixations on the individual level are established, two new levels of design fixation are proposed here, organisational and institutional design fixations. Even though most empirical studies on design fixation have been conducted on industrial or mechanical design [47], it seems reasonable to extrapolate the concept and apply it to higher levels of analysis. 


\subsection{Design Thinking to Overcome Design Fixation}

Design fixations are a bias to prior solutions or known concepts, whereas creativity is about producing novelty and usefulness [48]. In this paper, while acknowledging the existence of tested methods to overcome design fixation on the micro-level [47], we assume that the ability of design thinking to elicit creativity is a promising way to avoid and overcome design fixation. We premise that designers who apply design thinking are less susceptible to design fixations.

\subsection{Distinction between Limitations and Fixations}

It is important to distinguish between design fixations and limitations. Fixations are a form of blind adherence to existing concepts, which limits the possible outcomes of a design process [15]. The causes of a design fixation are controllable by the designer. As mentioned above, there are tools to overcome some of the design fixations.

Design limitations, on the other hand, are constraints that reduce the number of possible designs without the designer's controllability. They are preconditions given to the designer, for example, regulations, customer requirements, or supply chain limitations. One of the widely known examples of design limitations is found in remanufacturing. Third-party remanufacturers typically cannot change the designs of the cores they are dealing with and therefore face certain limitations. For instance, even if they find an improvement opportunity by changing the physical structure used, they cannot do so due to no access to the control of the design nor even to the design information of the entire core [49]. Even original equipment manufacturers are limited (timewise) to re-design anything after the cores return. This is supported by the common knowledge that the design (of products) for remanufacturing - based on the idea of "strike while the iron is hot"—is important [50]. Note that some opportunities exist for a third-party remanufacturer such as software updates, replacement with components with other functionalities; however, limitations exist regarding the extent of improvement compared to the freedom given to designers of the products [49]. The difference between design fixation and design limitation is depicted in Figure 1.
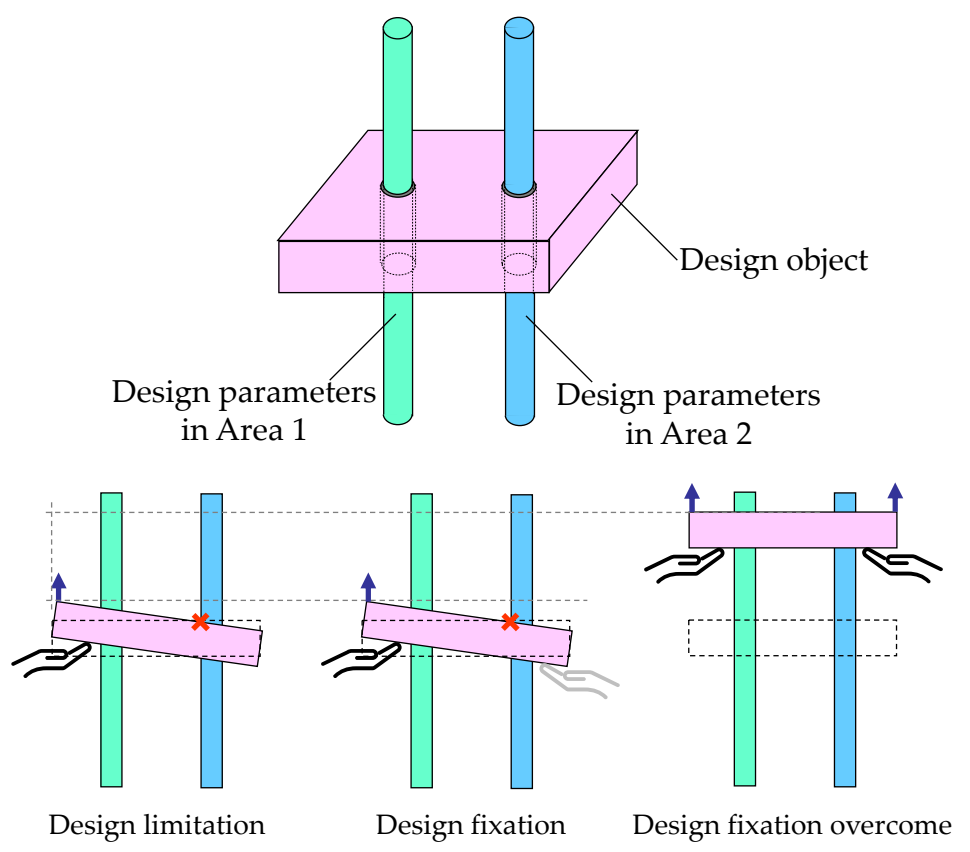

Figure 1. Distinction between limitation and fixation from the perspective of designing, building upon [51]. Note: Suppose the design object in question has two sets of design parameters, e.g., in the product area and the service area. A design limitation exists when the designer has control only in one of the areas. When the designer has control in both areas but does not use it in Area 2, fixation is observed. When the control in both areas is actually used effectively, the design fixation is overcome. 
The usefulness of this limitation-fixation dichotomy lies in its potential to increase creativity. A designer ought to carefully investigate whether he or she blindly adheres to known concepts. Once a design parameter is identified to be an object of a design fixation, better solutions can be found.

In this work, we refer to three levels of design fixation and design limitation. We suggest that design fixations are only preconceived constraints of the design space that can be overcome, whereas design limitations actually constrain the design within the design space.

Figure 1 shows a multilevel design space model. Design has a fractal characteristic; a designer faces level-specific fixations and limitations. In addition, design decisions on a higher level impact those on a lower one.

\subsection{Individual Level}

In design for sustainability, few publications report research on conceptual fixations on the individual level. For example, Collado-Ruiz and Ostad-Ahmad-Ghorabi [52] showed fixation effects and reduced creativity on designers by provided environmental information through experiments with university students. This research implies the possibility of the importance of providing relevant information avoiding fixation effects. This article aims to address the design of an STS, and hence, more conceptualisation is maintained for Sections 3.4 and 3.5.

\subsection{Organisational Level}

\subsubsection{Need to Combine Domain Expertise and Design Thinking}

Individual designers may meet both conceptual and knowledge fixations (Youmans, 2014). The latter may be especially relevant in industrial settings because design for sustainability requires knowledge in different subjects that each individual designer hardly covers comprehensively: a product designer is often responsible for specific components or aspects, and has acquired the expertise needed to solve technical issues with the components or aspects. Domain expertise is argued to lead to less flexibility in problem solving and idea generation [38]. However, other knowledge is required to achieve solutions from a holistic or lifecycle perspective, e.g., from resource depletion or ecotoxicity. Therefore, recent research has argued the need for an expert as a relevant knowledge holder to efficiently realise design for sustainability [53]. This need for a staff of a more generalist nature, with a holistic perspective, is common for the heavyweight product manager that is claimed to be a key role for higher quality products built by original equipment manufacturers in the traditional automotive manufacturing business [54].

Concerning conceptual fixations, Bjorklund and colleagues point out that in large industrial organisations with a dominance of employees with engineering backgrounds, the lack of design thinking awareness "boxes in" designers, making it hard for them to succeed internally with their ideas and designs [55]. Moreover, design thinkers are often spread throughout an organisation, without a strategic bundling of these design resources. This lack of "wide design" may confine design thinking work to the operational level [55]. Towards a solution for knowledge and conceptual fixations, the authors interpret the methodology suggested by Bocken, et al. [56] as a way to help companies overcome unsustainable design fixation of their business models. The method focusses on experimenting with the business model in order to achieve defined sustainability goals; by applying a systems perspective, the method considers interdependencies and interactions with other organisations.

\subsubsection{Organisational Structures Favouring Design Fixations}

Holistic design with a lifecycle perspective involves collaboration between multiple internal or external organisations, especially in large manufacturing companies, for example, departments for product development, marketing, maintenance and remanufacturing. Companies are often required to "think outside the box" in aiming at lifecycle-based offerings. Conceptual fixation, however, is often observed at large organisations in industry because of missing information flows (e.g., design for 
remanufacturing [57]), or missing engineering and management procedures (e.g., integration of product and service development [58]), or overreliance on information sharing of how design thinking works without subsequent actions [55]. Note that conceptual fixation is found also in small companies such as start-ups [59]: entrepreneurs are reported to search for a solution from resources already available, also known as effectuation [60].

In particular, potential causes for knowledge fixations were shown between product design and marketing in the context of product/service systems [40]: the insights from the two disciplines differ even for common themes such as business orientation, collaboration, cost aspects, flexibility, performance indicators, requirements and services.

In an industrial survey, a substantial portion of manufacturers with PSS offerings employed products that were originally designed for conventional product sales [61]. Thus, these companies' PSS designs were fixated on product sales-based designs. A recent study on PSS design in industry [58] reported the company's need for incorporating service aspects into product design when moving towards a solution provider (ibid., p. 2155). The separation between the product and service departments was reported not on an individual but rather an organisational level, causing the sub-optimisation of elements in the whole solution (ibid. p. 2158). The unequal size of the product and service departments was pointed out as one factor in companies with a strong legacy of technologies, and this may be interpreted as intentional resistance.

\subsubsection{Organisational-Level Design Limitations}

Design limitations on the organisational level were also reported. A study on barriers and enablers of small and medium-sized enterprises in the circular economy [62] stated that small- and medium-sized enterprises face multiple limitations stemming from their ecosystem when trying to design their business models for a circular economy. Major limitations stem from, e.g., a lack of support of supply and demand network, capital and government support. A manufacturer's design of a service-based washing machine offering is limited because the legal vehicle of leasing is highly regulated, i.e., the legal restriction of the lease period and lease rate limit the design space of the offering [12].

\subsection{Institutional Level}

\subsubsection{Institutions and Institutional Designers}

We use the term institution to describe the coordination and structuration of activities [21]. Institutions are the "rules" of the game. For Geels [21], rules and institutions refer to the same sociological concept. Similarly, we refer to institutions as the regulative dimension of rules; these are explicit formal rules that delineate legal from illegal actions and constrain behaviour [21]. We define an institutional-level design fixation as referring to blind adherence to known concepts when designing or re-designing regulative rules. This connects to the field of policy design.

Policies set the framework into which products and services need to fit, and policies determine the kinds of products and services that are legitimate. This makes policymaking an upstream part of the product and service design process [63] (see Figure 2). Similar to product designers, policy designers will face design fixations as well as limitations. Within this conceptual framework for design fixation, we conceptualise the design fixations and limitations in the context of policy design.

Policymakers can be considered designers of STSs, which are not designed from scratch but rather developed over a long period. This is natural, as STSs are typically partially designed and partially evolved [64]. Through policies, the actions and inactions of STS actors such as companies or consumers are shaped. For example, the sociotechnical transportation systems in countries like the Netherlands, Denmark or Germany are much bicycle-friendlier than the USA or UK. Pucher and Buehler [65] explain that, after realising the detrimental effects of increasing car traffic on health and the environment in cities, policymakers have designed policies that make bicycling more favourable than car use. A plethora of government policies has been implemented in these countries that explain the distinct shape of their 
sociotechnical transport systems, such as transport policies, land-use policies, urban development policies, housing policies, environmental policies, taxation and parking policies [65]. We imagine that each component of the sociotechnical transport system has been a part of the policy design process. This means that products and services, infrastructure, business models, and policies are all potential design parameters. From this perspective comparing outcomes of different STSs, it becomes clear that cities that managed to become bicycle-friendly have overcome design fixation that others could not, i.e., prioritising car traffic over other modes of transport [66].

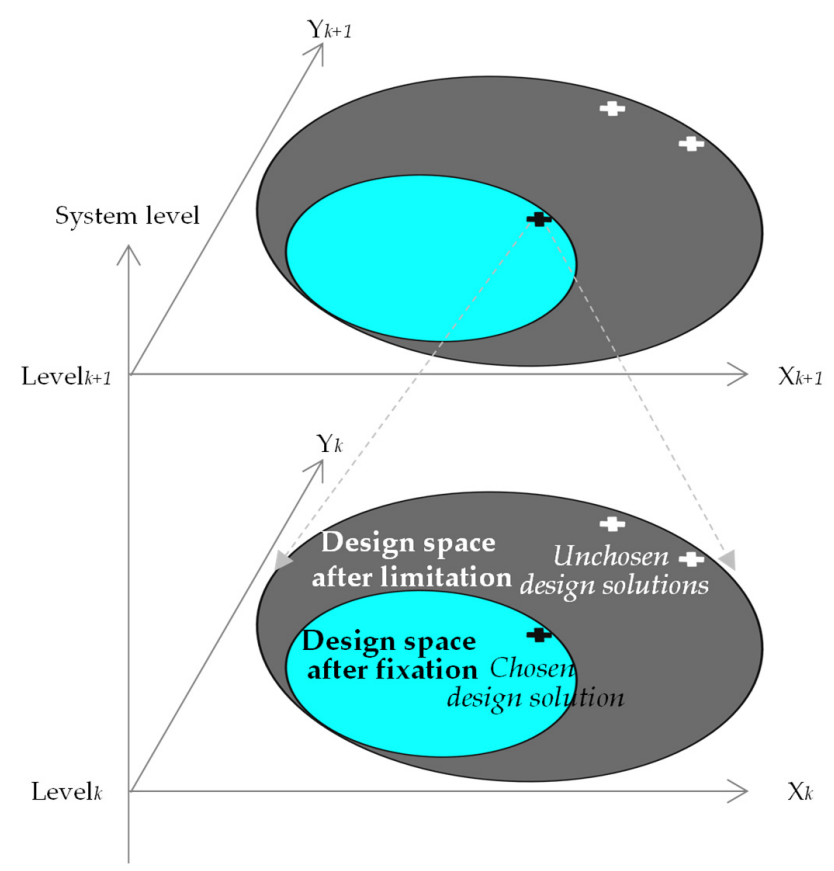

Figure 2. Presentation of design spaces given to different level. Note: A design solution on a higher system level is a factor to setting a space in which possible design alternatives are found (the design space after limitation). The dimensions on a level (depicted as $\mathrm{X}$ and $\mathrm{Y}$ axes) can be defined according to design objectives at the level. On each level, design fixation will create a nested space, in which a design solution is chosen. Outside the design space after fixation, other possible solutions are found. A level can be on the product design level, the business model design level, the institutional level, and other levels.

Public policies are crucial in STSs to create favourable conditions for innovations as well as to overcome path dependencies or lock-ins [67]. For example, technological niches are considered key to overcome STS lock-ins [67]. Niches, as shielded design spaces for the incubation and development of path-breaking innovations, are a tool to find alternative ways to solve societal problems. For example, policies can increase the value of eco-innovations or increase the costs of pollution or regulatory compliance can be the starting point for companies to invest into eco-innovations [68]. Given the scale of STS, public actors play a major role in their transformations. In the literature on design for system innovations and transitions [69], many design-thinking elements are of major importance.

\subsubsection{Policy Design and Design Thinking in Policy}

Policymaking, given its problem-solving-oriented character, has been identified as a design problem for decades [70,71]. Policymaking and policy design are not synonymous, yet policy design plays a major role in the policymaking process. The policy design literature is not entirely clear on where to delineate these concepts. For example, some scholars like to think that the design operates in an ideal space, where theory-based understandings of cause-effect relations are used to select optimal policy instruments for given goals. Others see that reality plays a larger role in policy design where partisan tactics, opportunism, and so on corrupt the design process [71]. 
Politicians and administrators, actors who hold authority, make policies. These actors base their decisions on the advice of trusted persons, experts or entire policy advice systems that consist of, for example, universities, think tanks and NGOs [71]. Public sector innovation (PSI) labs have also recently become a part of the policy advice system [72].

There is a notion that in order to tackle increasingly complex problems and decrease inefficiencies from top-down policymaking, it should become more creative and forward thinking [72]. Design thinking might be a suitable way to do so; see emerging research in, e.g., Vaz and Prendeville [73]. This is in line with the increasing popularity of design thinking in non-traditional fields like services, business models and policymaking [74]. Design thinking is being applied more and more in the public sector; in several countries, PSI labs are used to apply design thinking in the public sector [75] and develop public policies in a design thinking-oriented way.

PSI labs have been established around the world in countries like the UK, Australia, New Zealand and Denmark as vehicles to implement design thinking in the public sector [72]. Currently, PSI labs are implemented to find innovative and cheaper ways to offer government services [72]. Clarke and Craft [76] analyse the commensurability of design thinking and public policy design and find that whereas for some applications design thinking can help to produce solutions to wicked problems, it is no panacea in cases where the political-normative aspect is crucial or where multiple citizen interests have to be weighed against each other (e.g., the legalisation of marijuana). Compared to "evidence-based" policymaking, design thinking through participation and user-centeredness seems to be better at producing ethnographically informed insights and facilitation of collaboration, and in improving citizens' experiences of public services [77], but it is also less applicable for quantifying causal relations, which is often required by rational approaches to policymaking [75].

The PSI labs' design activities can be categorised into design for discrete problems, development of design thinking capability for public servants, design for consultation, and design of policies [72]. It seems that, currently, these labs are to a larger degree used for designing communication and improving consultation with stakeholders and less in the design of policies. It also appears that PSI labs are not all about applying design methods in the policymaking process; for some PSI labs, the main role is to introduce a design-oriented mindset into the public sector, i.e., user-centeredness, co-creation, and exploration [73], and design experts are employed to train policymakers to design thinking methods in order to improve innovation policies [78].

\subsubsection{Institutional Design Fixations}

Howlett (2014) shows that policy design has changed considerably in recent decades and that certain trends in the selection of policy instruments have been registered. Until the 1980s, governments followed more of a top-down approach. Since the era of Ronald Reagan and Margaret Thatcher, marketand network-based policies have become increasingly popular, which is based on the belief into the efficiency of markets [79]. The conventional centralised, top-down style of governance lost popularity and was deemed inefficient. This trend has led to a situation where certain policy instruments are considered outdated even though they may be more appropriate. This makes the research into institutional design fixations more relevant. Howlett indeed underlines that policymakers should be free in their instrument selection, or, in other words, overcome the design fixations posed by these trends. Design thinking in policy design supports this notion. Rational policymaking is based on technical expertise, participatory policymaking is based on democratic principles and design thinking is based and creativity and innovation [72].

However, design thinking cannot be fully exploited in institutional design due to its inherent characteristics. Clarke and Craft [76] outline specific shortcomings of the applicability of design thinking in policy design. Design thinking is blind to the politics of policy design. Whereas design thinking is useful to improve the user experience and citizens' engagement, which is beneficial for public services, it is not apt to handle the political challenge of weighing different interests. This is in contrast to discrete policy problems around public service delivery or specific policy implementation 
activities, which lend themselves very well to design thinking. Clarke and Craft also mention that design thinking is not scalable to larger systems; it cannot be scaled up to entire policy sectors or governments, where, in some instances, quick decisions need to be made, or because activities to ascertain user-centeredness and co-creation are too costly [76]. This implies that conventional policymaking has its merits and cannot be replaced by a design thinking-based way of policymaking. Another disadvantage mentioned is that design thinking considers policy designs as discrete artefacts.

In addition, policy design literature mentions that sometimes, the design process is tainted by politics or party interests, which limits policymakers [71]. No policy instrument operates independently, but rather functions as part of a mix of policies. Policy design is thought of as a rigorous process, including data gathering, modelling, systematically weighing different options and finally selecting and implementing policy instruments that are best suited to attain set policy goals [72]. In policy design, the choice of policy instruments is a central consideration because the instruments are what attains the defined policy goals "on the ground". Typically, policy instruments and their effects are influenced by other instruments. These policy mixes can be described by their consistency, coherence and congruence [76]. The issue of optimally designing policies to minimise instrument conflicts and maximise synergies is a key question in current policy design studies.

Clarke and Craft state that design thinking is particularly useful for policy problems that are clearly defined and which have already passed the political agenda-setting at the implementation stage, and where systems-thinking and networked approaches are sound for the given policy problem.

The institutional level is important for yet another reason. Institutions can be locked-in to certain technologies for the same reasons as companies [67]. Cecere, Corrocher, Gossart and Ozman [67] lists high fixed costs, learning effects, coordination effects and adaptive expectations. Foxon [80] points out that the potential of new technologies can only be realised if institutions enable it. An additional aspect is that institutions limit individuals in their options, including policymakers. If the institutional context is such that social innovations are hampered, radical policy options which are necessary for a sustainable future become unlikely [81].

\subsubsection{Institutional Design Limitations}

In every country, STSs have their own specific shape, for example, sociotechnical transport systems [82], sociotechnical laundry systems [83] or sociotechnical heating systems [20]. There is a limiting path dependence that every policymaker faces when trying to design a given policy.

We believe that apart from politics, the built environment, technology, and social norms contribute to path dependences that a policy designer has to consider and that ultimately limits the design. Borg and Högberg (2014) have shown that the built environment is essential for determining people's behaviour. In Sweden, people who have access to communal laundry facilities use them, even though they could afford individual machines [84]. Lock-in effects are categorised into increasing return effects and network externalities. Increasing return effects occur when there is a direct relation between resources invested in a technology and the gains from that technology. Network externalities occur when the usefulness of a technology increases with the number of its use cases. Increasing returns and network externalities can explain why inferior technologies persist in markets, e.g., VHS instead of beta max [85], or why there are human instead of automatised operators of air traffic control systems [9]. Each society has its own way of doing things. Social norms limit a policymaker's decision space in the sense that policy instruments have varying effectiveness, depending on the degree to which they cater to the population's social norms [86].

\section{Case Study: Design Fixation in the Sociotechnical Laundry System}

\subsection{Method}

The objective of this case study is to help the reader comprehend and envision multi-level design fixations with a proof of concept. To do so, a concrete case of laundry is introduced and 
thereby impacts of design fixations on resource efficiency and environmental loads are quantified. It will be shown that there are resource-saving opportunities because of multi-level design fixations towards individualistic laundry care. First, we will outline the STS around laundry activities with a literature-based identification of design fixations including the authors' own. Then, we present a simulation model that estimates the carbon emissions related to laundry.

The selected method is a based on System Dynamics [87]. The model stems from the authors' peer-reviewed publication [88] on a similar topic and was developed based on existing topical literature and interviews with industry experts. It adopts the data from public statistics sources (e.g., [89,90]) and interviews with industry experts, and is used to estimate the impact of design fixations on resource use and carbon emissions of the sociotechnical laundry system (STLS). System Dynamics is useful for this kind of study because it allows integration of quantitative (e.g., carbon intensity of electricity) as well qualitative aspects (e.g., user behaviour) which is necessary considering the diversity of components of STS.

The model contains stocks for households, as well as various types of washing machines used by households. The model population represents the people in Sweden living in flats. Based on the behavioural profiles of a given population, the model estimates the carbon emissions of the related laundry practices. For the carbon emissions, a life cycle perspective is applied that includes production, use phase, and end-of-life of the products.

The simulation model was validated as shown in the authors' earlier publication [88]

\subsection{Design Fixations and Limitations in the SLTS}

Laundry care as a part of personal hygiene has been realised on the societal level through a variety of STSs. In some countries, it is most common for people occupying a household to purchase a washing machine and wash all their laundry with it. In other countries, flat tenants share communal laundry facilities with their neighbours [84]. In densely populated areas, people use launderette washing machines and dryers on a pay-per-use basis. In other areas, some people use a service for laundry care. Finally, in a few countries, laundry care is still done by hand [91].

The social norm of how people do their laundry has a strong impact on the related resource consumption. In most Western countries, every household tends to have its own washing machine [92]; many countries are fixated on the idea of individual household laundry facilities. Burk shows that the shape of STSs is a compromise between the forces of societal needs, political power and technological developments [24]. The history of the sharing of communal laundry facilities in Sweden shows that rich Western countries can take a different path. In the 1950s, policies were designed that provided large parts of society with new laundry technology in communal facilities [93]. Today still, tenants are used to sharing washing machines with their neighbours and Swedish flat tenants exhibit a low ownership rate of washing machines compared to other Europeans [92]. The Swedish STLSs grew around these policies with companies developing long-lasting (i.e., durable), easy-to-maintain and high load rate capacity washing machines [94], and new buildings had dedicated spaces for the facilities [84]; eventually, it became the norm for Swedes living in flats to share laundry facilities. Starting from the housing policies in the 1950s, Swedish STLSs have arrived at today's relatively widespread practice of sharing of laundry facilities by not being fixated to individual ones with entailing resource savings.

In an STLS, many design parameters need to be compatible to make large-scale sharing behaviour possible. For example, a certain willingness of the tenants is required to accept the personal hygiene issues of sharing the machines, and building developers need to provide customised, long-lasting, energy-efficient washing machines. Washing machine manufacturers, in turn, need to develop the necessary business models, and policymakers may create a policy landscape to support this system [93]. However, today, with high living standards and changes in the individual perception of hygiene, more and more building developers opt to place laundry facilities in each flat instead of shared facilities in a central spot [84]. It has been observed before that both consumer preferences and political forces play a role in shaping STSs [24]. 


\subsection{Design Limitations of the STLS}

If a company offers an availability-based PSS such as "washing as a service", it has an incentive to design the machines to be long-lasting and cheap to maintain. The current legal vehicle to provide washing machines as a service is leasing contracts. However, the maximum duration and the lease payments may be regulated. The advantage of leasing washing machines is that people can have access to long-lasting, energy-efficient washing machines without facing high up-front costs that such premium machines usually entail. Regulations and standards (e.g., ISO) can be effective in making designers aware of new solutions and facilitate more efficient designs. A market study showed how quickly new energy labelling standards were adapted to by the washing machine market pushing inefficient devices out of the market [95].

Current service-based offerings [96,97] face limitations as well. The services are based on product platforms whose designs are not controlled by the provider. These offerings are limited to market-available designs.

\subsection{Scenarios Representing Sociotechnical Design Fixations}

Four scenarios were drafted (see Table 1) to demonstrate the role of design fixation for resource efficiency. We imagine that each scenario is an expression of a sociotechnical design fixation. The scenario "business as usual" represents the current situation where $50 \%$ of households have their own washing machine and $50 \%$ are sharing. Scenario A represents a sociotechnical design fixation that can be seen in several EU countries, where the large majority of households have their own retail washing machine. In scenario B, retail washing machines that are shared by multiple tenants cover their laundry needs. An advantage of this scenario is that the washing machines are utilised to a much larger degree. Scenario $C$ advances scenario $B$ with the aspect that the machines are not normal retail machines but rather so-called "semi-professional" adapted machines, which are 50\% heavier, long-lasting, easy to maintain, and with a large load rate resulting in a very low energy demand per $\mathrm{kg}$ washed [98], compared to a retail machine.

Table 1. Scenarios representing different design fixations and their simulation results.

\begin{tabular}{|c|c|c|c|c|}
\hline & Business as Usual & Scenario A & Scenario B & Scenario C \\
\hline $\begin{array}{c}\text { Organisational level (relative } \\
\text { to Scenario A) }\end{array}$ & Not applicable & Not applicable & Fixated & Fixation overcome \\
\hline $\begin{array}{c}\text { Accumulated } \mathrm{CO}_{2} \mathrm{eq} \\
\text { emissions in year } 2049 \text { (billion } \\
\left.\mathrm{kgCO}_{2} \mathrm{eq}\right)\end{array}$ & 2.66 & 4.52 & 3.92 & 1.54 \\
\hline $\begin{array}{c}\text { Total number washing } \\
\text { machines of retail or semi-prof. } \\
\text { washing machines produced } \\
\text { until year } 2049\end{array}$ & $\begin{array}{l}2.6 \text { mio retail }+0.12 \\
\text { mio semi-prof. }\end{array}$ & 6.2 mio retail & 4.1 mio retail & 0.44 mio semi-prof. \\
\hline
\end{tabular}

\subsection{Simulation Results}

The simulation results in Table 1 show the carbon emissions and the numbers of washing machines related to different STS shapes by the end of the simulation period in 2049. Scenario A causes the most emissions, followed by scenario $B$, which is based on sharing but using washing machines designed for individual household use. Scenario $C$ is the most environmentally friendly with $66 \%$ less emissions than scenario A. Comparing scenarios A and B, the effects of overcoming the fixation on the institutional level can be estimated; 2.1 million retail washing machines are saved as a proxy for 
resource use. For covering the model population's laundry needs, only 0.44 million washing machines are necessary in scenario C compared with 4.1 million washing machines in scenario B.

Although these are high-level estimations, they represent the effects from design fixations that account for substantial portions of the environmental loads. In the Swedish case, national building requirements lead to the widespread installation of communal washing machines. We attribute the difference of 0.6 billion $\mathrm{kg} \mathrm{CO}_{2}$ eq between scenario $\mathrm{A}$ and scenario $\mathrm{B}$ to the overcoming of institutional design fixations (e.g., inducing housing developers to construct communal laundry facilities). In addition, companies developed long-lasting durable, easy-to-maintain and high load rate capacity washing machines. Therefore, we attribute the difference of 2.38 billion $\mathrm{kg} \mathrm{CO}_{2}$ eq between scenario $\mathrm{B}$ to scenario $\mathrm{C}$ to the overcoming of organisational design fixations (e.g., design fixation towards offering predominantly individual retail machines). In other words, $20 \%$ of the difference between scenario $\mathrm{A}$ and C, can be attributed to overcoming institutional design fixation and $80 \%$ to overcoming organisational design fixation in this specific case.

By reshaping the STLS towards sharing, a substantial amount of carbon emissions can be saved. Sharing leads to less idling and a higher utilisation of resources. In scenarios A and B are only retail machines, the emissions are much higher than in the business-as-usual machines (50\% use semi-prof. machines) or those in scenario C (100\% semi-prof. machines). The semi-prof. washing machines are heavier but longer lasting, easier to maintain, and allow for larger load rates. Scenario $\mathrm{C}$ is the idealistic scenario; emissions are $42 \%$ lower than in the business-as-usual scenario.

The difference in carbon emissions is significant (see Figure 3). If all are sharing (green line), the least emissions are observed whereas when all households take an individualistic approach with retail machines, the most carbon emissions occur. The two sharing scenarios have lower starting values because the population uses fewer machines at any given time. The red line of scenario B exceeds the green (scenario C) and then the grey (business as usual) because initially the population uses relatively fewer machines. But these machines are of lower retail quality, have shorter lifespans than professional machines, need more frequent replacement, (also in scenario A-blue line), and their efficiency is lower compared to semi-professional machines, which are used in the business-as-usual context and scenario C.

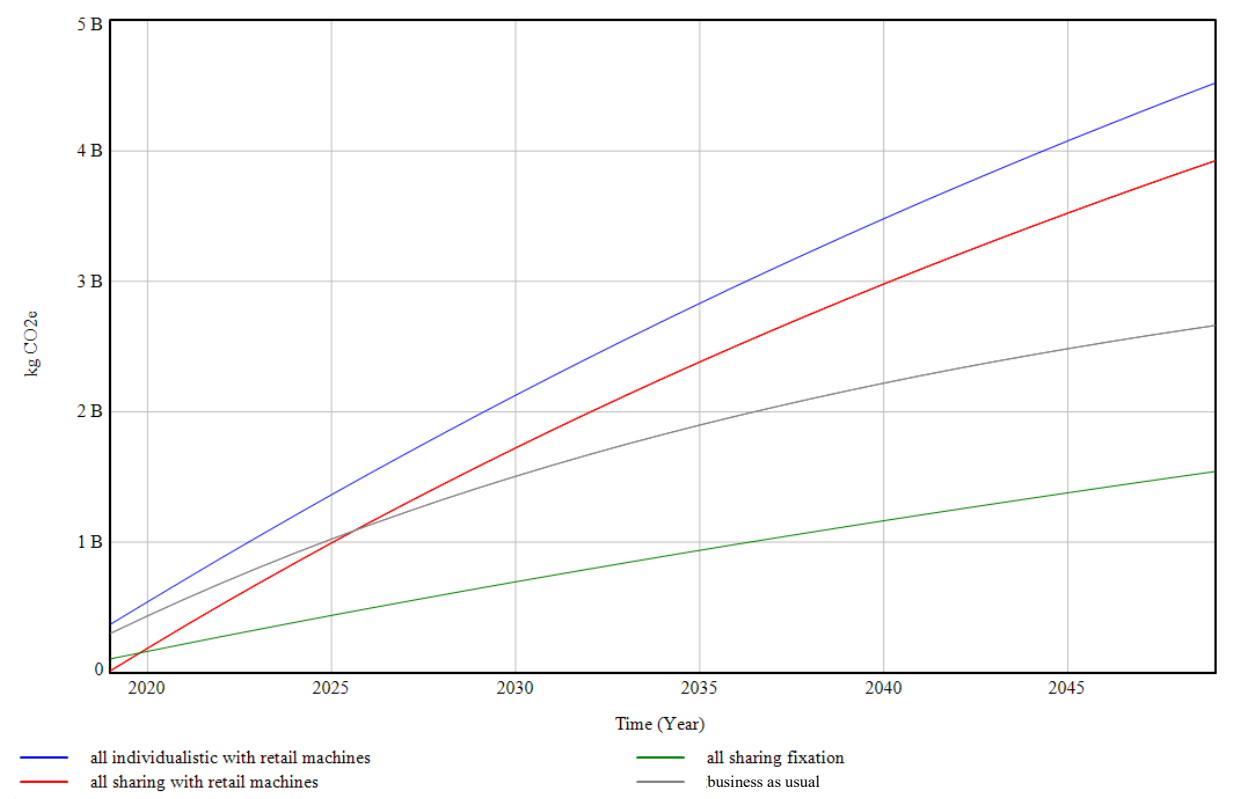

Figure 3. Total carbon emissions of the four scenarios (accumulated). Note: The stocks are well mixed. At any given time, old machines are discarded and new ones are added. Because a varying number of washing machines is used throughout the scenarios, which translates to the corresponding number of in- and outflows, the four scenarios have slightly differing starting values due to the different numbers and types of washing machines at the initial point. 


\section{Discussion}

\subsection{Contribution to Research on Design for Sustainability}

In design for sustainability, Ceschin and Gaziulusoy [69] synthesised the historical evolution of research focus from insular to systemic as well as from technology to people: the levels shifted from product [99], PSS [100], and spatio-social [101] to STS [82], according to its maturity for the last three decades. This article took a more nuanced view to addressing the STS by highlighting elements of business model [56] and governmental policy. Despite the higher potential for innovation, more PSSs remain to be implemented in our societies. This under-exploitation could be attributed to the lack of sophisticated ways to mitigate the risks inherent from providing PSSs [102] and barriers to implement PSSs [103]. This article sheds light on the inertia that seems to commonly exist in designing in our societies by applying the concept of design fixation. Thus, it enhanced understanding for supporting further implementation of PSSs and the improvement of STSs by clarifying what is (im)possible on a given level and showing that, when possible, fixation is a major challenge from the designing perspective. Figure 1 depicts the advancement in knowledge by enriching the representation of PSS design made in Sakao and Shimomura [51]. Thereby, this article contributed to a better understand of why implementing PSSs and improving STSs is challenging. By relating design fixation to the sustainability context, the existing body of knowledge for design fixation, such as how to avoid design fixation, can be applied to the sustainability challenge (see also Klotz, et al. [104] for designing built environments).

Furthermore, the effects of design fixation and design limitation on the environmental loads were estimated quantitatively with the case of washing clothes. Through scenario simulations, the effects of design fixations on resource use and carbon emissions have been demonstrated. The results suggest that many countries miss out on resource savings potentials because their STLSs are designed to cater to individualistic laundry behaviour. These insights are expected to help managers in industry and governments choose the right focus for the improvement of sustainability. Policymakers may overcome these design fixations and implement policies that allow for communal laundry facilities and the sharing of long-lasting semi-professional laundry machines, or that redefine socially-accepted cleanliness such that people wash less.

We would like to touch on the relevance of an alternative STS concept that is used to describe human-technology work systems. This STS concept was conceived by Trist and Bamforth [18] and is aimed to improve performance by understanding and designing the human-technology interfaces in organisations [105]. Even though established sociotechnical design principles [106,107] do not directly apply to our level of analysis, we would like to refer to the most relevant ones. The principle of compatibility [106] says that both the social and the technical dimension need to be compatible if an organisation is to achieve its objectives. This holds true for the sustainability field as well. If societal systems have differing objectives, they may be mutually exclusive. Minimal critical specification [106] relates very closely to design fixation. The principle states that whereas objectives need to be clearly specified, the means of how the objectives are achieved do not need to be specified. Too much specificity of how a task should be conducted closes options as well as new avenues a designer might have not considered. The incompletion principle of sociotechnical design [106] is recognisable in design for sustainability efforts as well. Because STSs are so complex and consist of a multitude of sub-systems, there is constant change and a need to adapt the design. For example, policymaking seems to be lagging behind ongoing developments in society. A policy framework for sustainability is continuously incomplete. Finally, on an update of the sociotechnical design principles, Clegg [107] states that "sociotechnical thinking" might be applied to larger organisational networks and Clegg, et al. [108] argue to extend the scope of STSs including culture, technology, infrastructure, people, goals and process in the design methods of STSs as well as to use simulation modelling to improve STS design. 


\subsection{Conceptualisation of Design Fixation on Higher Levels}

Crilly and Cardoso [36] pointed out that research on design fixation is in its infancy, and even a clear methodology on how to research this phenomenon is still missing. The authors presented a long list of 16 research gaps in the design fixation literature (ibid., pp. 1920-). In the context of the design of an STS for sustainability, what is highly relevant among those gaps are multidisciplinary teams, domain knowledge and scale; hence, this article focused on these three gaps. This article also conceptualised the design fixation on higher scales such as organisations and institutions, and thereby provided a greater understanding in particular to design fixations in teams and organisations as well as the scalability of the concept. This is expected to enhance the body of knowledge on design fixation $[15,47]$, which is to date largely based on experimental research of individual designers and informs little on real-world design [109]. On the organisational level, this article showed that the literature found that conceptual fixation occurred in large organisations [58] and that the knowledge fixation was found as an important gap [40] (see Section 3.4). On the institutional level, clear evidence of design fixations was not identified from the literature. However, policymaking has been identified as a design domain as well [71], and to assume that policymaking also exhibits design fixations seems only reasonable (see Section 3.5).

Design fixations, thus, may lead to conservative designs [36]. Conservative designs are related to several phenomena on higher levels of design, such as resistance to change [110], sub-optimisation and technological lock-in. To clarify the relations around these concepts, we introduced the design limitation in relation to design fixation. Both limit the design space, but design fixations can be overcome, whereas design limitations are constraints that need to be complied with during the design process. The contribution of this new conceptualisation lies in the awareness building across different disciplines; substantial insights of relevance were found available in design [15] and other disciplines $[38,55]$ and were related with each other. We expect that this article contributes to different research communities to further develop inter- or trans-disciplinary knowledge that is needed to solve urgent societal problems efficiently. Once it is recognised that a design parameter is an object to a design fixation, established tools, for example, prototyping or experimentation $[15,27]$, can be used to find better solutions.

We provide an estimation of the relative impact of organisational and institutional design fixations (see Section 4.4). It needs to be stated that these are rough estimations and that it may be difficult to pinpoint the single contributing factors. Readers are invited to make the analysis more accurate and further develop the debate that was initiated by this article.

\subsection{Limitations}

The presented study has limitations in terms of the methods used and number of cases studied. Whereas the quantification of the impact of design fixations on the environmental aspect (shown in Section 4) was estimated for one case with one method, the identified design fixations and limitations (shown in Section 3) are based on the analysis of relevant literature including the authors' own.

\section{Conclusions}

Design fixation and the many phenomena similar to it seem to be inherent to the human way of problem solving and designing. Designers should especially be aware of design fixation and learn methods to avoid it. Knowingly or unknowingly, everybody who designs may run into design fixations.

The purpose of this paper is to combine the concept of design fixation with higher levels of analysis, like the organisational and institutional contexts. On each level, there may be different reasons exacerbating design fixations. In an organisational context, we observed a series of causes for design fixation. The organisation's structure may lead to design fixation because of an imbalance in the power of the departments contributing to design, or second, because of an imbalance of deep domain knowledge with respect to wide knowledge (i.e., holistic or lifecycle perspective). The third cause for design fixation may be the hierarchical structure that hampers design thinkers from expressing 
their creativity. In the institutional context, policymakers do not just face individual design fixations. Past policy decisions have shaped the STSs that policymakers are dealing with into certain forms. To be specific, in some countries, the STLSs have been shaped by policies favouring communal facilities, whereas in other countries, a tradition of individualistic solutions makes it much harder to implement large-scale, resource-efficient solutions. Apart from path dependences stemming from the infrastructure/built environment, behavioural norms, technological developments and policy trends, policymakers also face policy legacies, that is, the existing policy framework; all these factors limit policymakers in the first place, and design fixations are only on top of that.

The environmental impact of design fixation has been estimated by means of a simulation model. In a series of scenarios, different design fixations were assumed and the related emissions estimated. The model applied a lifecycle perspective. The emissions savings potential of a communal way of fulfilling laundry needs has been shown to be substantial, up to $66 \%$ in this specific case.

This paper has created various interesting avenues for future research. As with every conceptualisation work, this work can be followed by concept operationalisation and concept evaluation. We expect that a potential next step on this road to operationalise design fixations on higher levels of analysis would need to describe more cases and develop methods to identify and analyse high-level design fixations. The analysis of interest will benefit from applying various theoretical lenses and granularities, and include also aspects other than the environment; e.g., the economy. We invite readers to bring cases into this endeavour and, in doing so, expect that stakeholders working on those levels, given their insider knowledge, play a major role in the identification and description of design fixations.

Author Contributions: Conceptualization, R.W. and T.S.; Methodology, R.W.; Writing-Original Draft Preparation, R.W. and T.S.; Writing-Review \& Editing, R.W. and T.S.; Visualization, T.S. All authors have read and agreed to the published version of the manuscript.

Funding: This research was funded by the European Commission under the Horizon 2020 Marie Skłodowska Curie Action 2016, grant number 721909. The APC was funded by the Linköping University Library.

Acknowledgments: Nathan Crilly of the University of Cambridge and Wisdom Kanda of Linköping University are acknowledged for their fruitful comments and discussions with an earlier version of this manuscript.

Conflicts of Interest: The authors declare no conflict of interest.

\section{References}

1. Ramani, K.; Ramanujan, D.; Bernstein, W.Z.; Zhao, F.; Sutherland, J.; Handwerker, C.; Choi, J.K.; Kim, H.; Thurston, D. Integrated Sustainable Life Cycle Design: A Review. J. Mech. Des. 2010, 132. [CrossRef]

2. Umeda, Y.; Takata, S.; Kimura, F.; Tomiyama, T.; Sutherland, J.W.; Kara, S.; Herrmann, C.; Duflou, J.R. Toward integrated product and process life cycle planning-An environmental perspective. Cirp Ann. 2012, 61, 681-702. [CrossRef]

3. Abdoli, S.; Kara, S.; Hauschild, M. System interaction, System of Systems, and environmental impact of products. Cirp Ann. Manuf. Technol. 2019, 68, 17-20. [CrossRef]

4. Ghisellini, P.; Cialani, C.; Ulgiati, S. A review on circular economy: The expected transition to a balanced interplay of environmental and economic systems. J. Clean. Prod. 2016, 114, 11-32. [CrossRef]

5. Tukker, A. Product services for a resource-efficient and circular economy-A review. J. Clean. Prod. 2015, 97, 76-91. [CrossRef]

6. Geissdoerfer, M.; Bocken, N.M.P.; Hultink, E.J. Design thinking to enhance the sustainable business modelling process-A workshop based on a value mapping process. J. Clean. Prod. 2016, 135, 1218-1232. [CrossRef]

7. Olsson, L. Sociotechnical System Studies of the Reduction of Greenhouse Gas Emissions from Energy and Transport Systems; Linköping University Electronic Press: Linköping, Sweden, 2015.

8. Kanda, W.; Sakao, T.; Hjelm, O. Components of business concepts for the diffusion of large scaled environmental technology systems. J. Clean. Prod. 2016, 128, 156-167. [CrossRef]

9. Spinardi, G. Up in the air: Barriers to greener air traffic control and infrastructure lock-in in a complex socio-technical system. Energy Res. Soc. Sci. 2015, 6, 41-49. [CrossRef] 
10. Bolton, R.; Foxon, T. Negotiating the Energy Policy 'Trilemma' —An Analysis of UK Energy Governance From a Socio-Technical Systems Perspective. In Theorising Governance Change for a Sustainable Economy; British Library: London, UK, 2013; pp. 1-24.

11. Brown, T. Design thinking. Harv. Bus. Rev. 2008, 86, 84-92,141.

12. Sakao, T.; Wasserbaur, R.; Mathieux, F. A methodological approach for manufacturers to enhance value-in-use of service-based offerings considering three dimensions of sustainability. Cirp Ann. Manuf. Technol. 2019, 68, 33-36. [CrossRef]

13. Jansson, D.G.; Smith, S.M. Design fixation. Des. Stud. 1991, 12, 3-11.

14. Goldschmidt, G. Avoiding Design Fixation: Transformation and Abstraction in Mapping from Source to Target. J. Creat. Behav. 2011, 45, 92-100. [CrossRef]

15. Youmans, R.J.; Arciszewski, T. Design fixation: Classifications and modern methods of prevention. AI EDAM 2014, 28, 129-137. [CrossRef]

16. Gero, J.S. Design prototypes: A knowledge representation schema for design. AI Mag. 1990, 11, 26.

17. Moreno, D.P.; Blessing, L.T.; Yang, M.C.; Hernandez, A.A.; Wood, K.L. Overcoming design fixation: Design by analogy studies and nonintuitive findings. AI EDAM 2016, 30, 185-199. [CrossRef]

18. Trist, E.L.; Bamforth, K.W. Some social and psychological consequences of the longwall method of coal-getting: An examination of the psychological situation and defences of a work group in relation to the social structure and technological content of the work system. Hum. Relat. 1951, 4, 3-38.

19. Hughes, T.P. The Evolution of Large Technological Systems. In The Social Construction of Technological Systems: New Directions in the Sociology and History of Technology; MIT Press: Cambridege, MA, USA, 1987; Volume 82.

20. Rohracher, H. A Sociotechnical Mapping of Domestic Biomass Heating Systems in Austria. Bull. Sci. Technol. Soc. 2016, 22, 474-483. [CrossRef]

21. Geels, F.W. From sectoral systems of innovation to socio-technical systems-Insights about dynamics and change from sociology and institutional theory. Res. Policy 2004, 33, 897-920. [CrossRef]

22. Kanda, W.; Kivimaa, P. What opportunities could the COVID-19 outbreak offer for sustainability transitions research on electricity and mobility? Energy Res. Soc. Sci. 2020, 68, 101666. [CrossRef]

23. Savaget, P.; Geissdoerfer, M.; Kharrazi, A.; Evans, S. The theoretical foundations of sociotechnical systems change for sustainability: A systematic literature review. J. Clean. Prod. 2019, 206, 878-892. [CrossRef]

24. Burk, D. Infrastructure, Social Practice, and Environmentalism: The Case of Bicycle-Commuting. Soc. Forces 2017, 95, 1209-1236. [CrossRef]

25. Brown, T.; Katz, B. Change by Design. J. Prod. Innov. Manag. 2011, 28, 381-383. [CrossRef]

26. Norman, D. The Design of Everyday Things: Revised and Expanded Edition; Basic Books: New York, NY, USA, 2013.

27. Ceschin, F. How the Design of Socio-technical Experiments Can Enable Radical Changes for Sustainability. Int. J. Des. 2014, 8, 1-21.

28. Heiskanen, E.; Hyvonen, K.; Laakso, S.; Laitila, P.; Matschoss, K.; Mikkonen, I. Adoption and Use of Low-Carbon Technologies: Lessons from 100 Finnish Pilot Studies, Field Experiments and Demonstrations. Sustainability 2017, 9, 847. [CrossRef]

29. Dijk, M.; de Kraker, J.; Hommels, A. Anticipating Constraints on Upscaling from Urban Innovation Experiments. Sustainability 2018, 10, 2796. [CrossRef]

30. Plattner, H.; Meinel, C.; Leifer, L. Design Thinking Research; Springer: Berlin, Germany, 2018. [CrossRef]

31. Cole, R.J.; Oliver, A.; Robinson, J. Regenerative design, socio-ecological systems and co-evolution. Build Res. Inf. 2013, 41, 237-247. [CrossRef]

32. Finster, M.; Eagan, P.; Hussey, D. Linking Industrial Ecology with Business Strategy: Creating Value for Green Product Design. J. Ind. Ecol. 2001, 5, 107-125. [CrossRef]

33. Baldassarre, B.; Schepers, M.; Bocken, N.; Cuppen, E.; Korevaar, G.; Calabretta, G. Industrial Symbiosis: Towards a design process for eco-industrial clusters by integrating Circular Economy and Industrial Ecology perspectives. J. Clean. Prod. 2019, 216, 446-460. [CrossRef]

34. Clune, S.J.; Lockrey, S. Developing environmental sustainability strategies, the Double Diamond method of LCA and design thinking: A case study from aged care. J. Clean. Prod. 2014, 85, 67-82. [CrossRef]

35. Shapira, H.; Ketchie, A.; Nehe, M. The integration of Design Thinking and Strategic Sustainable Development. J. Clean. Prod. 2017, 140, 277-287. [CrossRef] 
36. Crilly, N.; Cardoso, C. Where next for research on fixation, inspiration and creativity in design? Des. Stud. 2017, 50, 1-38. [CrossRef]

37. Purcell, A.T.; Gero, J.S. Drawings and the design process. Des. Stud. 1998, 19, 389-430. [CrossRef]

38. Dane, E. Reconsidering the Trade-Off between Expertise and Flexibility: A Cognitive Entrenchment Perspective. Acad. Manag. Rev. 2010, 35, 579-603. [CrossRef]

39. Waldman, M. Durable goods theory for real world markets. J. Econ. Perspect. 2003, 17, 131-154. [CrossRef]

40. Brambila-Macias, S.A.; Sakao, T.; Kowalkowski, C. Bridging the gap between engineering design and marketing: Insights for research and practice in product/service system design. Des. Sci. 2018, 4. [CrossRef]

41. Luchins, A.S. Mechanization in problem solving: The effect of Einstellung. Psychol. Monogr. $1942,54$. [CrossRef]

42. Smith, S.M.; Linsey, J. A Three-Pronged Approach for Overcoming Design Fixation. J. Creat. Behav. 2011, 45, 83-91. [CrossRef]

43. Altshuller, H. And Suddenly the Inventor Appeared: The Art of Inventing: How to Invent and Solve Technical Problems; Technical Innovation Center: Hagerstown, MD, USA, 1994.

44. Dong, A.; Sarkar, S. Unfixing Design Fixation: From Cause to Computer Simulation. J. Creat. Behav. 2011, 45, 147-159. [CrossRef]

45. Gordon, W.J.J. Synectics: The Development of Creative Capacity; Harper: Oxford, UK, 1961; p. xi, 180.

46. Crilly, N. Fixation and creativity in concept development: The attitudes and practices of expert designers. Des. Stud. 2015, 38, 54-91. [CrossRef]

47. Alipour, L.; Faizi, M.; Moradi, A.M.; Akrami, G. A review of design fixation: Research directions and key factors. Int. J. Des. Creat. Innov. 2018, 6, 22-35. [CrossRef]

48. Sarkar, P.; Chakrabarti, A. Assessing design creativity. Des. Stud. 2011, 32, 348-383. [CrossRef]

49. Whalen, K.A.; Milios, L.; Nussholz, J. Bridging the gap: Barriers and potential for scaling reuse practices in the Swedish ICT sector. Resour. Conserv. Recy. 2018, 135, 123-131. [CrossRef]

50. Hatcher, G.D.; Ijomah, W.L.; Windmill, J.F.C. Design for remanufacture: A literature review and future research needs. J. Clean. Prod. 2011, 19, 2004-2014. [CrossRef]

51. Sakao, T.; Shimomura, Y. Service Engineering: A novel engineering discipline for producers to increase value combining service and product. J. Clean. Prod. 2007, 15, 590-604. [CrossRef]

52. Collado-Ruiz, D.; Ostad-Ahmad-Ghorabi, H. Influence of environmental information on creativity. Des. Stud. 2010, 31, 479-498. [CrossRef]

53. Brambila-Macias, S.A.; Sakao, T. Effective Ecodesign Implementation with the Support of a Lifecycle Engineer. J. Clean. Prod. 2020, 279, 123520. [CrossRef]

54. Fujimoto, T. Product Integrity and the Role of DESIGNER-AS-INTEGRATOR. Des. Manag. J. Former Ser. 2010, 2, 29-34. [CrossRef]

55. Bjorklund, T.; Maula, H.; Soule, S.A.; Maula, J. Integrating Design into Organizations: The Coevolution of Design Capabilities. Calif. Manag. Rev. 2020, 62, 100-124. [CrossRef]

56. Bocken, N.; Boons, F.; Baldassarre, B. Sustainable business model experimentation by understanding ecologies of business models. J. Clean. Prod. 2019, 208, 1498-1512. [CrossRef]

57. Lindkvist, H.; Sundin, S. Feedback from Remanufacturing: Its Unexploited Potential to Improve Future Product Design. Sustainability 2019, 11, 4037. [CrossRef]

58. Matschewsky, J.; Kambanou, M.L.; Sakao, T. Designing and providing integrated product-service systems-challenges, opportunities and solutions resulting from prescriptive approaches in two industrial companies. Int. J. Prod. Res. 2018, 56, 2150-2168. [CrossRef]

59. Crilly, N. 'Fixation' and 'the pivot': Balancing persistence with flexibility in design and entrepreneurship. Int. J. Des. Creat. Innov. 2017, 6, 52-65. [CrossRef]

60. Sarasvathy, S.D. Causation and Effectuation: Toward a Theoretical Shift from Economic Inevitability to Entrepreneurial Contingency. Acad. Manag. Rev. 2001, 26, 243-263. [CrossRef]

61. Sakao, T.; Napolitano, N.; Tronci, M.; Sundin, E.; Lindahl, M. How are product-service combined offers provided in Germany and Italy? Analysis with company sizes and countries. J. Syst. Sci. Syst. Eng. 2008, 17, 367. [CrossRef]

62. Rizos, V.; Behrens, A.; van der Gaast, W.; Hofman, E.; Ioannou, A.; Kafyeke, T.; Flamos, A.; Rinaldi, R.; Papadelis, S.; Hirschnitz-Garbers, M.; et al. Implementation of Circular Economy Business Models by Small and Medium-Sized Enterprises (SMEs): Barriers and Enablers. Sustainability 2016, 8, 1212. [CrossRef] 
63. Junginger, S. Design and innovation in the public sector: Matters of design in policy-making and policy implementation. Annu. Rev. Policy Des. 2013, 1, 1-11.

64. De Weck, O.L.; Roos, D.; Magee, C.L. Engineering Systems: Meeting Human Needs in a Complex Technological World; MIT Press: Cambridege, MA, USA, 2011.

65. Pucher, J.; Buehler, R. Making cycling irresistible: Lessons from the Netherlands, Denmark and Germany. Transp. Rev. 2008, 28, 495-528. [CrossRef]

66. Shepherd, S.P. A review of system dynamics models applied in transportation. Transp. B Transp. Dyn. 2014, 2, 83-105. [CrossRef]

67. Cecere, G.; Corrocher, N.; Gossart, C.; Ozman, M. Lock-in and path dependence: An evolutionary approach to eco-innovations. J. Evol. Econ. 2014, 24, 1037-1065. [CrossRef]

68. Maitre-Ekern, E.; Dalhammar, C. Regulating Planned Obsolescence: A Review of Legal Approaches to Increase Product Durability and Reparability in Europe. Rev. Eur. Comp. Int. Environ. Law 2016, 25, 378-394. [CrossRef]

69. Ceschin, F.; Gaziulusoy, I. Evolution of design for sustainability: From product design to design for system innovations and transitions. Des. Stud. 2016, 47, 118-163. [CrossRef]

70. Linder, S.H.; Peters, B.G. From social theory to policy design. J. Public Policy 1984, 4, 237-259.

71. Howlett, M. From the 'old' to the 'new' policy design: Design thinking beyond markets and collaborative governance. Policy Sci. 2014, 47, 187-207.

72. Lewis, J.M.; Mcgann, M.; Blomkamp, E. When design meets power: Design thinking, public sector innovation and the politics of policymaking. Policy Politics 2020, 48, 111-130. [CrossRef]

73. Vaz, F.; Prendeville, S. Design as an Agent for Public Policy Innovation. Conf. Proc. Acad. Des. Innov. Manag. 2019, 2. [CrossRef]

74. Papalambros, P.Y. Design Science: Why, What and How. Des. Sci. 2015, 1, 1-38. [CrossRef]

75. McGann, M.; Blomkamp, E.; Lewis, J.M. The rise of public sector innovation labs: Experiments in design thinking for policy. Policy Sci. 2018, 51, 249-267. [CrossRef]

76. Clarke, A.; Craft, J. The twin faces of public sector design. Gov. Int. J. Policy Adm. Inst. 2019, 32, 5-21. [CrossRef]

77. Mintrom, M.; Luetjens, J. Design Thinking in Policymaking Processes: Opportunities and Challenges. Aust. J. Public Adm. 2016, 75, 391-402. [CrossRef]

78. Melazzini, M.; Campodall'Orto, S.; Carella, G.; Vignati, A.; Zurlo, F. Design Thinking Methods to Activate Co-creation Process Among Policymakers, Creative Industries and SMEs. In Proceedings of the II International Triple Helix Summit, Dubai, UAE, 10-13 November 2018.

79. Djelic, M.-L.; Sahlin-Andersson, K. Marketization: From Intellectual Agenda to Global Policy-Making. In Transnational Governance; Cambridge University Press: Cambridge, UK, 2006; pp. 53-73. [CrossRef]

80. Foxon, T.J. A coevolutionary framework for analysing a transition to a sustainable low carbon economy. Ecol. Econ. 2011, 70, 2258-2267. [CrossRef]

81. Kanda, W.; Hjelm, O.; Mejia-Dugand, S. Promoting the export of environmental technologies: An analysis of governmental initiatives from eight countries. Environ. Dev. 2016, 17, 73-87. [CrossRef]

82. Geels, F.W. The dynamics of transitions in socio-technical systems: A multi-level analysis of the transition pathway from horse-drawn carriages to automobiles (1860-1930). Technol. Anal. Strateg. Manag. 2005, 17, 445-476. [CrossRef]

83. Pettersen, I.N.; Boks, C.; Tukker, A. Framing the role of design in transformation of consumption practices: Beyond the designer-product-user triad. Int. J. Technol. Manag. 2013, 63, 70-103. [CrossRef]

84. Borg, L.; Hogberg, L. Organization of Laundry Facility Types and Energy Use in Owner-Occupied Multi-Family Buildings in Sweden. Sustainability 2014, 6, 3843-3860. [CrossRef]

85. Park, S. Quantitative analysis of network externalities in competing technologies: The VCR case. Rev. Econ. Stat. 2004, 86, 937-945. [CrossRef]

86. Gupta, M.; Esmaeilzadeh, P.; Uz, I.; Tennant, V.M. The effects of national cultural values on individuals' intention to participate in peer-to-peer sharing economy. J. Bus. Res. 2019, 97, 20-29. [CrossRef]

87. Sterman, J. Business Dynamics: Systems Thinking and Modeling for a Complex World; Irwin/McGraw-Hill: Boston, MA, USA, 2000. 
88. Wasserbaur, R.; Sakao, T.; Ljunggren Söderman, M.; Plepys, A.; Dalhammar, C. What if everyone becomes a sharer? A quantification of the environmental impact of access-based consumption for household laundry activities. Resour. Conserv. Recycl. 2020, 158, 104780. [CrossRef]

89. SCB. Living Conditions Surveys (ULF/SILC). Available online: https://www.scb.se/hitta-statistik/statistikefter-amne/levnadsforhallanden/levnadsforhallanden/undersokningarna-av-levnadsforhallanden-ulf-silc/ (accessed on 6 March 2019).

90. Eurostat. Population Projections at National Level (2015-2080). Available online: https://ec.europa.eu/ eurostat/data/database?node_code=proj (accessed on 10 March 2019).

91. Retamal, M.; Schandl, H. Dirty Laundry in Manila: Comparing Resource Consumption Practices for Individual and Shared Laundering. J. Ind. Ecol. 2017, 22, 1389-1401. [CrossRef]

92. Pakula, C.; Stamminger, R. Electricity and water consumption for laundry washing by washing machine worldwide. Energy Effic. 2010, 3, 365-382. [CrossRef]

93. Lund, K. Tvättstugan: En Svensk Historia; Nordiska Museets Förlag: Stockholm, Sweden, 2009. (In Swedish)

94. Electrolux. A Uniquely Swedish Way of Washing Your Clothes. Available online: https://www.electroluxgroup. com/en/a-uniquely-swedish-way-of-washing-your-clothes-29699/ (accessed on 16 October 2019).

95. Michel, A.; Attali, S.; Bush, E. Energy Efficiency of White Goods in Europe: Monitoring the Market with Sales Data; topten.eu: Zurich, Switzerland, 2015.

96. Homie. HOMIE Pay Per Use-Rent a Washing Machine. Available online: https://www.homiepayperuse.com/ (accessed on 25 September 2020).

97. Bosch. Home | BlueMovement. Available online: https://www.bluemovement.nl/default.aspx?nr=11 (accessed on 23 November 2018).

98. Electrolux. Front Load Washers-Electrolux Professional. Available online: https://professional.electrolux. com/commercial-laundry-equipment/front-load-washers/ (accessed on 23 November 2018).

99. Fiksel, J.R. Design for Environment; McGraw-Hill: New York, NY, USA, 1996.

100. Mont, O.K. Clarifying the concept of product-service system. J. Clean. Prod. 2002, 10, 237-245. [CrossRef]

101. Manzini, E. Making Things Happen: Social Innovation and Design. Des. Issues 2014, 30, 57-66. [CrossRef]

102. Sakao, T.; Rönnbäck, A.Ö.; Sandström, G.Ö. Uncovering benefits and risks of integrated product service offerings-Using a case of technology encapsulation. J. Syst. Sci. Syst. Eng. 2013, 22, 421-439. [CrossRef]

103. Vezzoli, C.; Ceschin, F.; Diehl, J.C.; Kohtala, C. New design challenges to widely implement 'Sustainable Product-Service Systems'. J. Clean. Prod. 2015, 97, 1-12. [CrossRef]

104. Klotz, L.; Weber, E.; Johnson, E.; Shealy, T.; Hernandez, M.; Gordon, B. Beyond rationality in engineering design for sustainability. Nat. Sustain. 2018, 1, 225-233. [CrossRef]

105. Pasmore, W.; Winby, S.; Mohrman, S.A.; Vanasse, R. Reflections: Sociotechnical Systems Design and Organization Change. J. Chang. Manag. 2019, 19, 67-85. [CrossRef]

106. Cherns, A. The principles of sociotechnical design. Hum. Relat. 1976, 29, 783-792. [CrossRef]

107. Clegg, C.W. Sociotechnical principles for system design. Appl. Ergon. 2000, 31, 463-477. [CrossRef]

108. Clegg, C.W.; Robinson, M.A.; Davis, M.C.; Bolton, L.E.; Pieniazek, R.L.; McKay, A. Applying organizational psychology as a design science: A method for predicting malfunctions in socio-technical systems (PreMiSTS). Des. Sci. 2017, 3, e6. [CrossRef]

109. Crilly, N. Creativity and fixation in the real world: A literature review of case study research. Des. Stud. 2019, 64, 154-168. [CrossRef]

110. Crilly, N. The Structure of Design Revolutions: Kuhnian Paradigm Shifts in Creative Problem Solving. Des. Issues 2010, 26, 54-66. [CrossRef]

(C) 2020 by the authors. Licensee MDPI, Basel, Switzerland. This article is an open access article distributed under the terms and conditions of the Creative Commons Attribution (CC BY) license (http://creativecommons.org/licenses/by/4.0/). 